\title{
Increased levels of Porphyromonas gingivalis are associated with ischemic and hemorrhagic cerebrovascular disease in humans: an in vivo study
}

\author{
Janaina Salomon GHIZONI', Luís Antônio de Assis TAVEIRA ${ }^{2}$, Gustavo Pompermaier GARLET ${ }^{3}$, Marcos Flávio \\ GHIZONI $^{4}$, Jefferson Ricardo PEREIRA ${ }^{5}$, Thiago José DIONÍSIO ${ }^{6}$, Daniel Thomas BROZOSKI ${ }^{7}$, Carlos Ferreira \\ SANTOS $^{8}$, Adriana Campos Passanezi SANT'ANA ${ }^{9}$
}

\begin{abstract}
1- DDS, MSc, PhD student, Discipline of Oral Pathology, Bauru School of Dentistry, University of São Paulo, Bauru, SP, Brazil.
2- DDS, MSc, PhD, Associate Professor, Discipline of Oral Pathology, Bauru School of Dentistry, University of São Paulo, Bauru, SP, Brazil.

3- DDS, MSc, PhD, Associate Professor, Discipline of Histology, Bauru School of Dentistry, University of São Paulo, Bauru, SP, Brazil.

4- MD, MSc, PhD, Associate Professor, Discipline of Neurosurgery, University of Southern of Santa Catarina - UNISUL, Tubarão, SC, Brazil.

5- DDS, MSc, PhD, Associate Professor, Discipline of Prosthodontics, University of Southern of Santa Catarina - UNISUL, Tubarão, SC, Brazil.

6- Laboratory Specialist, MSc, Discipline of Pharmacology, Bauru School of Dentistry, University of São Paulo, Bauru, SP, Brazil.

7- Postdoctoral Fellow, PhD, Discipline of Pharmacology, Bauru School of Dentistry, University of São Paulo, Bauru, SP, Brazil.

8- DDS, MSc, PhD, Professor, Discipline of Pharmacology, Bauru School of Dentistry, University of São Paulo, Bauru, SP, Brazil.

9- DDS, MSc, PhD, Associate Professor, Discipline of Periodontology, Bauru School of Dentistry, University of São Paulo, Bauru, SP, Brazil.
\end{abstract}

Corresponding address: Prof. Dr. Carlos F. Santos - Faculdade de Odontologia de Bauru - USP - Departamento de Ciências Biológicas - Disciplina de Farmacologia - Alameda Dr. Octávio Pinheiro Brisolla, 9-75 - Bauru - São Paulo - 17012-901 - Brazil - Phone: +55 1432358282 - Fax: +55 1432234679 e-mail: cebola@usp.br

Received: October 27, 2011 - Modification: November 26, 2011 - Accepted: November 27, 2011

\section{ABSTRACT}

$\mathrm{O}$ bjective: This study investigated the role of periodontal disease in the development of stroke or cerebral infarction in patients by evaluating the clinical periodontal conditions and the subgingival levels of periodontopathogens. Material and Methods: Twenty patients with ischemic (I-CVA) or hemorrhagic (H-CVA) cerebrovascular episodes (test group) and 60 systemically healthy patients (control group) were evaluated for: probing depth, clinical attachment level, bleeding on probing and plaque index. Porphyromonas gingivalis and Aggregatibacter actinomycetemcomitans were both identified and quantified in subgingival plaque samples by conventional and real-time PCR, respectively. Results: The test group showed a significant increase in each of the following parameters: pocket depth, clinical attachment loss, bleeding on probing, plaque index and number of missing teeth when compared to control values ( $p<0.05$, unpaired t-test). Likewise, the test group had increased numbers of sites that were contaminated with $P$. gingivalis $(60 \% \times 10 \%$; $\mathrm{p}<0.001$; chi-squared test) and displayed greater prevalence of periodontal disease, with an odds ratio of 48.06 ( $95 \%$ CI: $5.96-387.72 ; p<0.001$ ). Notably, a positive correlation between probing depth and the levels of $P$. gingivalis in ischemic stroke was found $(r=0.60$; $\mathrm{p}=0.03$; Spearman's rank correlation coefficient test). A. actinomycetemcomitans DNA was not detected in any of the groups by conventional or real-time PCR. Conclusions: Stroke patients had deeper pockets, more severe attachment loss, increased bleeding on probing, increased plaque indexes, and in their pockets harbored increased levels of $P$. gingivalis. These findings suggest that periodontal disease is a risk factor for the development of cerebral hemorrhage or infarction. Early treatment of periodontitis may counteract the development of cerebrovascular episodes.

Key words: Periodontal diseases. Stroke. Infection. Pathogenesis. Atherogenesis. 


\section{INTRODUCTION}

Recent findings suggest that atherogenesis and plaque rupture, two critical elements of cardiovascular pathogenesis leading to chronic disease burden and clinical events, result from systemic and vascular inflammatory processes ${ }^{42}$. In general, infections and low-grade inflammatory processes influence the development of atherosclerosis and ischemic lesions. Moreover, an association between atherogenesis and Porphyromonas gingivalis and Aggregatibacter actinomycetemcomitans, both anaerobic Gram-negative bacteria, has been demonstrated $8,14-16,26$.

Periodontal disease, an asymptomatic chronic infectious and inflammatory condition, harbors large numbers of anaerobic Gramnegative pathogens, including $P$. gingivalis and A. actinomycetemcomitans. In particular, when bacteria live in periodontal pockets lined with a thin and ulcerated epithelium as opposed to living on healthy gingival tissue with a robust epithelium, they can more effectively invade connective tissue, endothelial cells and the bloodstream. Additionally, these bacteria can induce thrombus formation by platelet aggregation degrading collagen ${ }^{28}$.

The main prerequisite for atherogenesis induction by periodontal disease may be the chronic systemic exposure to periodontopathic bacteria ${ }^{45}$ through bacteremia or endotoxemia, which stimulates the migration of inflammatory cells within major blood vessels walls, preceding the formation of atherosclerotic plaques in cerebral vessels ${ }^{35}$. Another mechanism for atherogenesis is the induction of immunological processes, leading to increased levels of C-reactive protein (CRP), and increases in CRP even within the range of normal values is considered a reliable predictor of cardiovascular disease (CVD) ${ }^{12,46}$. In brief, periodontal disease is associated with CVDs in casecontrols and prospective studies, and, additionally, more severe attachment loss, deepened pockets and increased numbers of missing teeth in patients was positively correlated with CVD $23,31,38,53,56$. Some studies found the presence of $P$. gingivalis and $A$. actinomycetemcomitans in carotid atherosclerotic plaques, but the role of periodontopathogens in atheroma formation remains unclear. Recent CVD association studies, which use measurements that capture clinical findings of periodontal disease and inflammatory measurements as exposures, generally exhibit stronger association than just clinical parameters of disease show ${ }^{5,40,42}$.

With these findings in mind, the aim of this study was to investigate the role of periodontal disease in the development of stroke or cerebral infarction in patients by evaluating the clinical periodontal conditions and the subgingival levels of periodontopathic bacteria.

\section{MATERIAL AND METHODS}

\section{Sample selection}

This study was approved by the Ethics Committee of Nossa Senhora da Conceição Hospital (Tubarão, SC, Brazil). Eighty patients, 30 to 80 years of age, were invited to participate in this study. Totally edentulous and/or pregnant patients and those patients whose formal consents were unobtainable were ineligible. The test group was composed of 20 randomly selected patients ( 12 men, 8 women) from the Neurosurgery Division of the Intensive Care Unit between January 2006 and December 2006. More specifically, the first 20 random patients that looked for hospitalization without any previous history of a cerebrovascular accident (CVA) were included in the test group. To be included in the test group, patients had to be diagnosed with ischemic or hemorrhagic stroke for up to 4 days after hospitalization. The control group in this study was comprised of the first 60 random patients (30 men, 30 women) from the city of Bauru, São Paulo, Brazil seeking dental treatment at the Operative Dentistry Clinics of the Bauru School of Dentistry, University of São Paulo, during the same time period as the test group. Age and gender-matched patients without previous or current history of stroke were included in the control group.

Patients included in the test group were randomly procured at the city of Tubarão (SC), while those included in the control group were randomly selected among the population of Bauru (SP). Considering the demographic features of the different populations, a proportion of 1 case to 3 controls was established, being in agreement with other studies that investigated the influence of periodontal disease in other systemic conditions ${ }^{13,30,43}$

Before data collection, patients answered a health questionnaire investigating possible risk factors for stroke, including: genetic predisposition, smoking, systemic alterations, arterial hypertension, and cardiovascular problems. Smoking was not evaluated in packs per years, but only evaluated whether the patient smoked. All patients were tested the same way.

\section{Clinical examination}

A single periodontist evaluated all patients by examining pocket probing depth (PPD) as measured by a manual periodontal probe (Hu-Friedy, USA), clinical attachment level (CAL), bleeding on/during probing $(B O P)^{1}$ and a dichotomous plaque index (PLI). For statistical purposes, the presence of $\mathrm{BOP}$ and dental plaque was recorded as 1 and their 
absence was recorded as 2. Additionally, although a whole mouth examination was performed, data were only recorded from the tooth showing the deepest pocket in each sextant. More specifically, the deepest site was evaluated after probing 3 buccal and 3 palatal sites of all the teeth in the volunteers. Data collection was confined to only one tooth in each sextant since most patients were lying on a bed unconscious making data collection arduous.

\section{Subgingival plaque sample}

Subgingival plaque samples were collected from the deepest site of each patient by introducing absorbent paper strips (PerioPaper, OraFlow Inc., NY, USA) for one minute into the gingival sulcus to the base of the pocket ${ }^{36}$. After removal, the material was stored in a sterile centrifuge tube containing $500 \mu \mathrm{L}$ of sterile distilled water and kept in a $-20^{\circ} \mathrm{C}$ freezer until DNA extraction.

\section{PCR analysis}

For DNA extraction, samples were diluted $1: 2$ with sterile distilled water and collected by centrifugation at $10,000 \times g$ for $5 \mathrm{~min}$ in a centrifuge at $4^{\circ} \mathrm{C}$. The supernatant was discarded and the resulting pellet was washed two times with $1 \mathrm{~mL}$ of sterile distilled water, reconstituted with $100 \mu \mathrm{L}$ of sterile distilled water and $100 \mu \mathrm{L}$ of InstaGene Matrix (Bio-Rad Laboratories, Inc., Hercules, CA, USA), and incubated at $56^{\circ} \mathrm{C}$ for $30 \mathrm{~min}$. Samples were then vortexed and boiled for $10 \mathrm{~min}$. After centrifugation to remove unbroken cells and large debris $(10,000 \times g$ for $3 \mathrm{~min})$, the supernatant was collected for PCR analysis ${ }^{47}$.

For conventional PCR, a total of $50 \mu \mathrm{L}$ of PCR mixture was analyzed. This mixture contained $10 \mu \mathrm{L}$ of DNA sample, $5 \mu \mathrm{L}$ of $10 \mathrm{X}$ PCR buffer, 1.25 units of Taq DNA polymerase (Promega, Madison, WI, USA), $0.2 \mathrm{mM}$ each of deoxyribonucleotides, $1.0 \mu \mathrm{M}$ of each primer, and $1.5 \mathrm{mM}$ of $\mathrm{MgCl}_{2}$ for $P$. gingivalis or $1.0 \mathrm{mM}$ of $\mathrm{MgCl}_{2}$ for $A$. actinomycetemcomitans ${ }^{47}$. DNA samples of $P$. gingivalis and $A$. actinomycetemcomitans were used as positive controls for amplifying reactions. These positive control samples were obtained from clinical isolations. For each set of primers, PCR was performed on sterile distilled water to check for DNA contamination (negative controls). Primer sequences (Figure 1) and temperature profiles were used as previously described ${ }^{4,55}$. PCR amplification products $(9 \mu \mathrm{L})$ were analyzed using $2 \%$ agarose gel electrophoresis stained with $0.5 \mu \mathrm{g} / \mathrm{mL}$ ethidium bromide and photographed under ultraviolet light. A 100 bp DNA ladder served as the molecular weight marker.

Real-time PCR was performed as previously described $^{20}$ with a MiniOpticon system (Bio-Rad, Hercules, CA, USA), using SybrGreen MasterMix (Invitrogen Life Technologies, Carlsbad, CA, USA), specific primers, and 50 ng of DNA in each reaction. The positivity of bacteria detection in each sample was determined by comparison with positive and negative controls. The results were analyzed according to the cycle threshold $\left(C_{t}\right)$ values. The number of bacteria in each sample and the $\mathrm{C}_{t}$ values were compared with a standardized curve composed from bacterial DNA ranging from $10^{-3}$ to $10^{9}$ bacteria.

\section{Statistical analysis}

Periodontal conditions of test and control groups were compared using an unpaired $t$-test. The prevalence of $P$. gingivalis and $A$. actinomycetemcomitans detected by conventional PCR was evaluated by a chi-squared test, with a $95 \%$ confidence level. The quantity of $P$. gingivalis and $A$. actinomycetemcomitans DNA quantified by real-time PCR were not normally distributed and were found to be consistent with a log normal distribution in the case of $P$. gingivalis, and thus comparisons were made using the KolmogorovSmirnov test. The risk of the occurrence of stroke influenced by periodontal disease was expressed as an odds ratio (OR), with a $95 \%$ confidence level. The correlation of periodontal parameters and the bacterial DNA levels were analyzed using a Spearman's rank correlation coefficient test.

\section{RESULTS}

In the test group of 20 patients, 7 (35\%) patients developed hemorrhagic cerebrovascular episodes (H-CVE) and 13 (65\%) patients developed ischemic cerebrovascular episodes (I-CVE). Data were obtained from 720 sites in the test group recovering from stroke and 2,158 sites in the control group (Table 1 depicts the periodontal conditions of the test and control groups). The prevalence of $P$. gingivalis and $A$. actinomycetemcomitans in the

\begin{tabular}{|c|c|c|c|c|}
\hline Target & Sense & Antisense & TA $\left({ }^{\circ} \mathbf{C}\right)$ & bp \\
\hline A. actinomycetemcomitans & ATGCCAACTTGACGTTAAAT & AAACCCATCTCTGAGTTCTTCTTC & 60 & 557 \\
\hline P. gingivalis & AGGCAGCTTGCCATACTGCG & ACTGTTAGCAACTACCGATGT & 59 & 127 \\
\hline
\end{tabular}

TA - annealing temperature; bp - base pairs

Figure 1- Primer sequences used in PCR tests and respective anneding temperature and the predicted amplicon size 
Table 1- Clinical periodontal conditions of test and control group patients (t-test)

\begin{tabular}{ccc}
\hline Parameter & Test Group & Control Group \\
\hline Age (years) & $59 \pm 13$ & $48 \pm 10$ \\
PPD $(\mathrm{mm})$ & $2.6 \pm 2.4$ & $2.4 \pm 1.5$ \\
CAL $(\mathrm{mm})$ & $5.1 \pm 4.4^{*}$ & $3.2 \pm 2.6$ \\
BOP $(\mathrm{mm})$ & $1.1 \pm 0.2^{*}$ & $1.7 \pm 0.8$ \\
PLI & $1.0 \pm 0.0^{*}$ & $1.8 \pm 0.4$ \\
Teeth missing & $2.4 \pm 1.6^{*}$ & $1.0 \pm 1.2$ \\
\hline
\end{tabular}

PPD - pocket probing depth (mm); CAL - clinical attachment level (mm); BOP - bleeding on probing (scores: 1 - presence; 2 - absence); PLI - dichotomous plaque index (scores: 1- presence; 2 - absence). Test and control values are reported as means \pm one SEM. *Significantly different from control, $p<0.001$

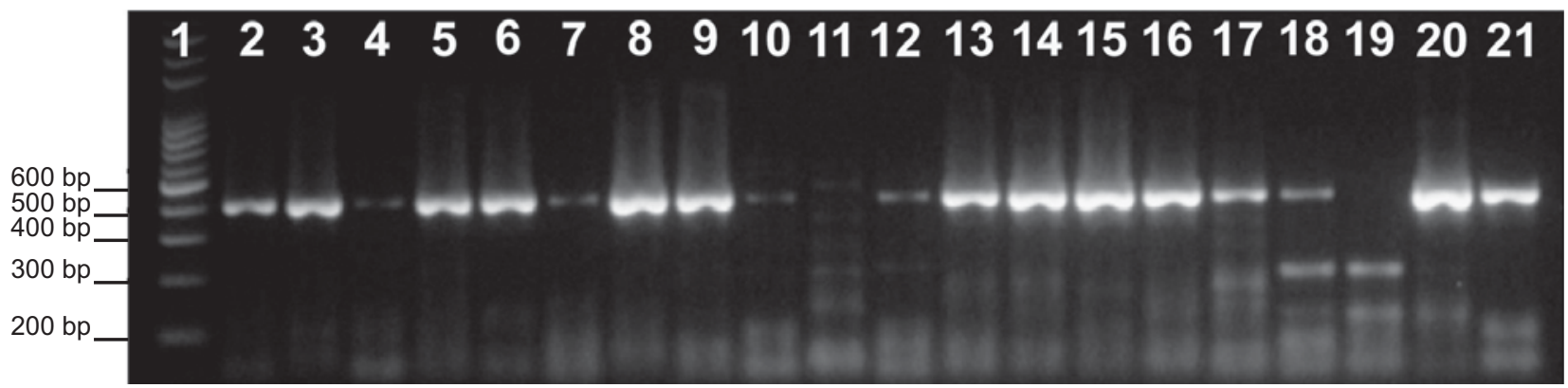

Figure 2- Detection of $P$. gingivalis, DNA using $2 \%$ agarose gel electrophoresis. The gel shows staining for $P$. gingivalis DNA amplified by conventional PCR from test group subjects. Lane 1 - contains the $100 \mathrm{bp}$ molecular weight marker; lanes 2 to 10,12 to 18,20 to 21 : positive staining for $P$. gingivalis DNA; columns 11 and 19 - negative samples for $P$. gingivalis

subgingival microbiota of test and control groups evaluated by conventional PCR demonstrated that, respectively, $60 \%$ and $10 \%$ showed the presence of $P$. gingivalis (chi-squared test, $\mathrm{p}<0.001$, Figure 2 ). A. actinomycetemcomitans DNA was not detected in any of the groups by conventional or real-time PCR.

The levels of $P$. gingivalis detected by real-time PCR are illustrated in Figure 3. Kolmogorov-Smirnov test showed a greater prevalence of $P$. gingivalis in the test group compared to the control group $(p<0.001)$.

In this study, periodontal disease was specifically defined by the presence of at least one site showing a $P P D \geq 4 \mathrm{~mm}$, which resulted in 19 (95\%) diseased patients in the test group and $17(28.3 \%)$ patients in the control group, resulting in an unadjusted odds ratio of 48.06 ( $95 \%$ confidence interval: 5.96 to $387.72, p<0.001)$.

The test group included 7 smoking patients $(35 \%), 5$ of which developed I-CVE and 2 of which developed H-CVE (data not shown), while the control group included 17 smoking patients (28.3\%) (Figure 4). An analysis showed that smoking did not have a significant influence on attachment loss in the test group (chi-squared test, $p<0.05$ ), although a significant influence was observed in the control group with respect to smoking (data not shown).

By separating ischemic (I-CVE, $n=13$ ) and

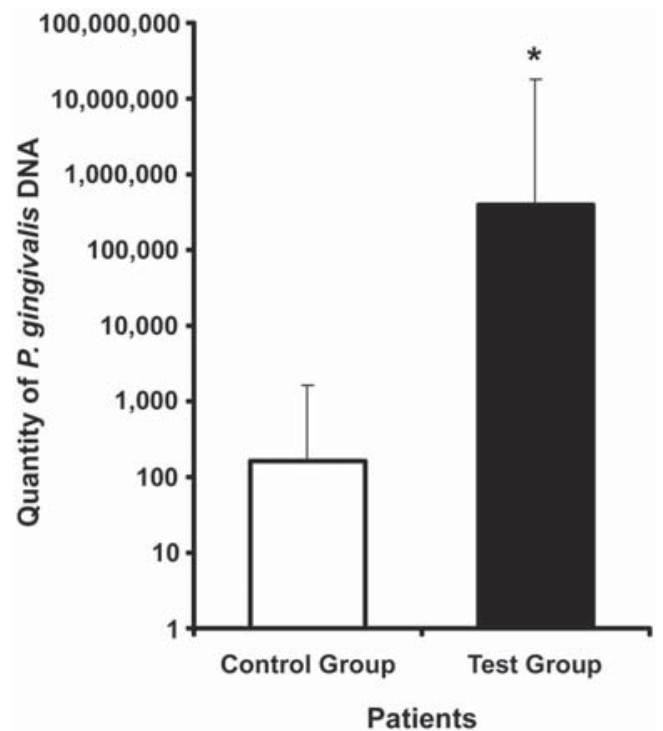

Figure 3- Quantification of $P$. gingivalis DNA detected in subgingival plaque samples from test and control group subjects using real-time PCR. These data were not normally distributed and were found to be consistent with a log normal distribution, and thus comparisons were made using the Kolmogorov-Smirnov test and depicted on a log scale using median with the error bars representing a distribution between the $2.5^{\text {th }}$ percentile and the $97.5^{\text {th }}$ percentile. ${ }^{*} D=1.0000$ with a corresponding $p<0.001$ compared to control 


\begin{tabular}{|c|c|c|c|}
\hline Patient & Age & Stroke & Parameters \\
\hline$A$ & 63 & I-CVE & $\mathrm{PD}, \mathrm{H}, \mathrm{S}$ \\
\hline$B$ & 52 & $\mathrm{H}-\mathrm{CVE}$ & $\mathrm{PD}, \mathrm{H}, \mathrm{S}$ \\
\hline $\mathrm{C}$ & 36 & $\mathrm{H}-\mathrm{CVE}$ & $\mathrm{PD}, \mathrm{H}$ \\
\hline$D$ & 56 & I-CVE & $\mathrm{PD}, \mathrm{H}$ \\
\hline$E$ & 55 & $\mathrm{H}-\mathrm{CVE}$ & $\mathrm{PD}, \mathrm{H}$ \\
\hline $\mathrm{F}$ & 72 & $\mathrm{H}-\mathrm{CVE}$ & $\mathrm{PD}, \mathrm{H}$ \\
\hline $\mathrm{G}$ & 48 & I-CVE & $\mathrm{PD}, \mathrm{H}$ \\
\hline $\mathrm{H}$ & 61 & I-CVE & $\mathrm{PD}, \mathrm{H}$ \\
\hline 1 & 69 & I-CVE & $\mathrm{PD}, \mathrm{H}, \mathrm{S}$ \\
\hline $\mathrm{J}$ & 71 & $\mathrm{H}-\mathrm{CVE}$ & $\mathrm{PD}, \mathrm{H}$ \\
\hline $\mathrm{K}$ & 59 & I-CVE & PD \\
\hline $\mathrm{L}$ & 35 & $\mathrm{H}-\mathrm{CVE}$ & $\mathrm{PD}, \mathrm{H}, \mathrm{S}$ \\
\hline$M$ & 56 & I-CVE & $\mathrm{PD}, \mathrm{H}, \mathrm{S}$ \\
\hline $\mathrm{N}$ & 78 & I-CVE & $\mathrm{PD}, \mathrm{H}, \mathrm{S}$ \\
\hline $\mathrm{O}$ & 80 & I-CVE & $\mathrm{PD}, \mathrm{H}$ \\
\hline $\mathrm{P}$ & 57 & I-CVE & $\mathrm{PD}, \mathrm{H}$ \\
\hline Q & 41 & I-CVE & PD, H \\
\hline $\mathrm{R}$ & 78 & I-CVE & $\mathrm{PD}, \mathrm{H}, \mathrm{S}$ \\
\hline$S$ & 60 & $\mathrm{H}-\mathrm{CVE}$ & PD \\
\hline $\mathrm{T}$ & 48 & I-CVE & $\mathrm{H}$ \\
\hline
\end{tabular}

I-CVE - ischemic cardiovascular episode; H-CVE - hemorrhagic cardiovascular episode; PD - periodontal disease; H hypertension; S - smoker

Figure 4- Health questionnaire results

Table 2- Periodontal status and levels of $P$. gingivalis detected by real-time PCR in ischemic (I-CVE) and hemorrhagic (H-CVE) cardiovascular episode

\begin{tabular}{cccc}
\hline Parameter & I-CVE & H-CVE & p-value \\
\hline PPD $(\mathrm{mm})$ & $2.7 \pm 2.4^{*}$ & $2.3 \pm 2.4$ & 0.009 \\
CAL $(\mathrm{mm})$ & $5.4 \pm 4.4^{*}$ & $4.4 \pm 4.4$ & 0.005 \\
BOP $(\mathrm{mm})$ & $1.1 \pm 0.3$ & $1.0 \pm 0.0$ & 0.47 \\
Teeth missing & $2.8 \pm 1.6$ & $2.3 \pm 2.4$ & 0.12 \\
P. gingivalis & $1.2 \times 10^{6} \pm 2.2 \times 10^{6 *}$ & $1.1 \times 10^{7} \pm 1.6 \times 10^{6}$ & 0.036 \\
\hline
\end{tabular}

PPD - pocket probing depth $(\mathrm{mm})$; CAL - clinical attachment level $(\mathrm{mm})$; BOP - bleeding on probing (scores: 1 - presence; 2 - absence); PLI- plaque index (scores: 1 - presence; 2 -absence); $P$. gingivalis - level of $P$. gingivalis. Test and control values are reported as means \pm one SEM. *Significantly different from control, $p<0.05$
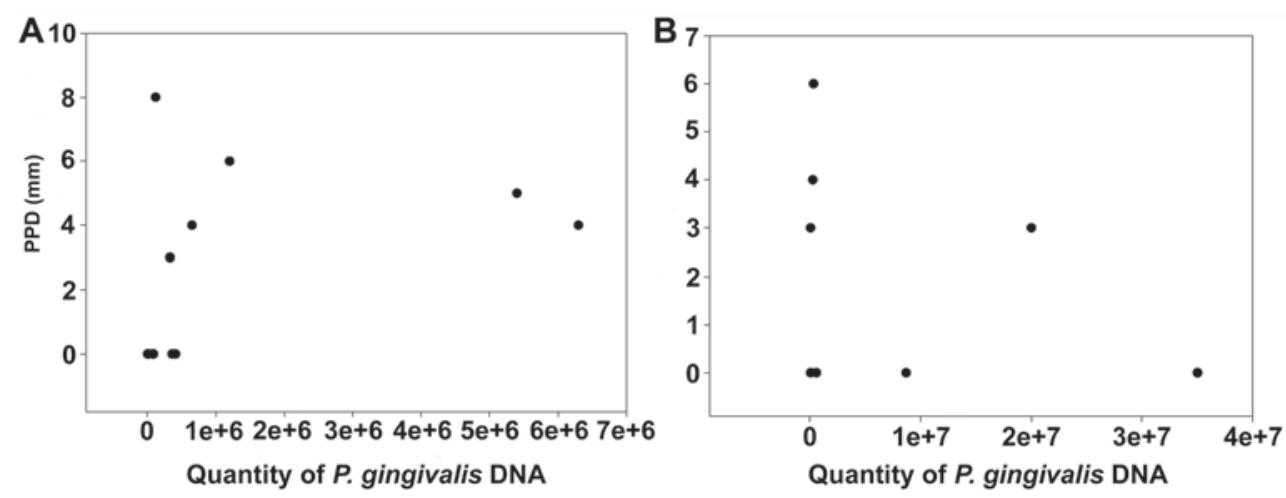

Figure 5- Correlation between the quantity of $P$. gingivalis DNA detected in subgingival plaque samples and pocket probing depth (PPD) from either $A$ ) ischemic cerebrovascular episodes (I-CVA), $r=0.60, p=0.03$; or $B$ ) hemorrhagic cerebrovascular episodes (H-CVA), r=0.24, $\mathrm{p}=0.09$. 
hemorrhagic ( $\mathrm{H}-\mathrm{CVE}, \mathrm{n}=7$ ) patients, increased PPD and CAL were observed in the I-CVE group, while increased levels of $P$. gingivalis were detected in the $\mathrm{H}$-CVE group $(\mathrm{p}<0.05)$. No significant differences were observed between subgroups in BOP and number of missing teeth ( $p>0.05$, Table 2$)$. A positive correlation between PPD and the prevalence of $P$. gingivalis $(r=0.60, p=0.03)$ was observed in the I-CVE group (Figure 5A); however this finding was not observed in the H-CVE group $(p=0.09$, Figure 5B).

\section{DISCUSSION}

This study tested the hypothesis that periodontal disease is a risk factor for the development of stroke, since patients with this condition show significant increases in CAL, BOP, PLI and $P$. gingivalis density compared to systemically healthy patients.

Some studies $23,28,31,38,45,53,56$ identified periodontal disease as a risk factor for the development of other medical conditions. The association between periodontal disease, tooth loss, and stroke was evaluated in epidemiological and prospective studies $^{18,23,31,38,52,53,56}$, suggesting an association between both, corroborating the findings of this study.

Periodontal disease remains a prevalent condition among many different populations ${ }^{2,29}$. Generally, more severe cases seem to be concentrated in $20 \%$ of the population ${ }^{2}$, while individuals at older age groups seem to present nearly $8 \%$ of severe periodontal disease ${ }^{29}$. For the present study, it was observed that 17 out of 60 patients in the control group and 19 out of 20 patients in the test group presented at least one periodontal pocket $\geq 4 \mathrm{~mm}$, resulting in a non-adjusted odds ratio of 48.06 (confidence interval: 5.96 to $387.72, p<0.001$ ). In brief, the cause-effect relationship between both conditions needs further investigation, but the findings of this study indicated that patients with stroke showed more prevalent and severe periodontal lesions than systemically healthy patients.

Stroke has been associated with an incidence of fever resulting from respiratory tract infections ${ }^{35,38}$. Also, stroke may play a role in odontogenic alterations ${ }^{26}$, and can be regarded as a predisposing factor for cerebral conditions linked to bacterial endocarditis ${ }^{45}$. In the present study, 13 out of 20 patients in the test group developed ischemic stroke and 7 out of 20 patients developed a hemorrhagic cerebrovascular event. Furthermore, bacterial counts were significantly increased in hemorrhagic versus ischemic stroke, suggesting to that bacteria can lead not only atheromatous plaque formation $8,14-16,26,28,32,41,45$, but also the invasion of endothelial cells and injury to blood vessels ${ }^{23,35,38}$.
Some studies suggested that the traditional role of lipid imbalance in the risk of cardiovascular diseases represents only one of the pathogenic pathways for CVD. In particular, a second pathway may be represented by inflammation ${ }^{25}$. This inflammation can induce CVD by impairing endothelial function, promoting plaque formation and favoring plaque rupture by compromising the structural integrity of atheromatous plaques through the induction of vascular instability, leading to increased susceptibility for ischemic and hemorrhagic events ${ }^{25}$

Dental sites with deep pockets harbor a large number of bacteria ${ }^{49}$, with a positive correlation between pocket probing depth and bacterial levels during ischemic stroke in the present study. Additionally, a greater incidence of ischemic stroke was previously observed in young patients with periodontal disease, particularly in those with decreased numbers of remaining teeth, however occurrence of this condition is unusual for younger age groups ${ }^{52,53}$.

Some studies have suggested an incidence of stroke in $10 \%$ of patients younger than 55 years ${ }^{39}$ and $3.9 \%$ in patients younger than 45 years ${ }^{33}$. The definition of the age limit for consideration of stroke in young adults is not established, with some young patients (less than 45 years old) showing and incidence of stroke from unknown causes. Zétola, et al. in 2001 found that out of 141 young patients with stroke, $32 \%$ had undetermined etiology 58 . For these reasons, the minimum and maximum age for inclusion of patients in the test and control groups was, respectively, 30 and 80 years. However, the average age of patients in the test group ( $59 \pm 13$ years) showed a trend to be older than the control group ( $48 \pm 10$ years), and this trend might suggest that the majority of patients older than 30 years were developing stroke. In this study, only 2 patients younger than 40 years of age had stroke.

Periodontal disease, in general, is quite prevalent in the world population. Estimates indicate that $20 \%$ of the world population have severe cases of periodontal disease ${ }^{2}$. In a sample of 600 individuals aged 20 to 70 years, Hugoson and Jordan ${ }^{29}$ (1982), found an incidence of about $11 \%$ of marginal periodontal infectious disease in healthy individuals between 30 and 40 years of age ${ }^{29}$. This suggests that in the age group of 40 years old there will be approximately $89 \%$ of healthy individuals who have gingivitis or mild periodontal disease, with no signs of bone loss. Only $8 \%$ of individuals between 40 and 70 years of age had severe periodontal disease ${ }^{29}$.

Although the number of patients included in the control group was relatively large compared to the number of patients in the test group yet in proportion, the increased number of patients in the control group provided more accurate information 
concerning periodontal conditions in the otherwise healthy patients. However, increasing the number of patients included in the plaque sample, especially for the test group, could have also potentially provided more accurate information for the periodontal conditions for ischemic or hemorrhagic stroke. Overall, the results obtained in this study were significantly different between test and control groups $(p<0.001)$, suggesting that periodontal disease is more prevalent and more severe in stroke than in systemically healthy patients, which is corroborated by other studies.

Periodontal examinations were performed by a single experienced periodontist, but a Kappa test was not performed to determine accuracy of this single examiner. Considering that periodontal examination of test group patients was performed bedside, time permitted only the tooth showing the deepest pocket at each sextant to be recorded, although a whole mouth examination was performed. Other risk factors for stroke were considered, in particular smoking. The results obtained in this study showed no differences between smoking and non-smoking patients.

Progression of periodontal disease is characterized by acute bursts 22,50 , with the conversion of lymphocytes to neutrophils ${ }^{21,27}$. The etiology of periodontal disease is multifactorial, but primarily related to host response interactions and specific bacterial species, including $P$. gingivalis and $A$. actinomycetemcomitans (the two bacteria which were investigated in this study $)^{44}$. These bacteria have been extensively investigated due to their pathological properties, which include their capacity for: invading connective tissue, epithelial and endothelial cells; activating the complement cascade and immune system; and stimulating the synthesis of cytokines and other inflammatory mediators ${ }^{14,34,49}$. Recently, these species were identified in atheromatous plaques of CVD patients $8,14,16,26,32,57$, suggesting a possible role for $P$. gingivalis and $A$. actinomycetemcomitans in the development of this lesion.

Both bacteria have their niche in the subgingival region, but they can also be found in lesser amounts in supragingival plaque samples ${ }^{24,49}$. However, their prevalence is not observed in all subgingival sites in the oral cavity, since healthy or inactive sites harbor extremely low populations of these bacteria 24,51 . Correspondingly, both bacteria are infrequently observed in the general population, but increased population densities are observed in patients with periodontal disease ${ }^{24,51}$. Although saliva is considered an easy, reliable and safe method to allow DNA identification by $\mathrm{PCR}^{47,55}$, some studies $^{4,7,9}$ have suggested that a higher prevalence of bacteria is detected from subgingival microbiota, as found in this study.
In the present study, the presence and quantity of these bacteria in subgingival plaque samples were investigated by conventional and real-time PCR. The results obtained showed that $P$. gingivalis was more prevalent in the test group than in the control group, and that $A$. actinomycetemcomitans could not be detected in either group. The absence of observable $A$. actinomycetemcomitans is intriguing and needs further investigation since the primers used in the PCR worked well for the positive controls (ATCC 29522) and in a previous work by our group to detect $A$. actinomycetemcomitans from saliva samples of children ${ }^{47}$.

Overall, the findings of this study are in agreement with other reports in the literature $18,23,26,31,38,52,53,56$, suggesting an association of periodontal disease and tooth loss with an increased risk of stroke. The increased levels of $P$. gingivalis in stroke patients could suggest a role for periodontopathic bacteria in the formation of atheromatous plaque and vascular lesions, thus increasing the risk of cardiovascular and cerebrovascular diseases.

Chronic infections, such as periodontal disease, can contribute to atherogenesis by direct (platelet aggregation, invasion and injury to endothelial cells) or indirect (synthesis of intracellular adhesion molecules, production of antibodies against bacterial LPS and an imbalance of the immune system) pathways ${ }^{3,19}$. Namely, it was observed in this study that the I-CVE group had increased pocket depth and attachment loss when compared to the H-CVE group, which showed significant increases in the population density of $P$. gingivalis. The composition of the subgingival microbiota in patients with periodontal disease provides a significant and persistent bacterial challenge to the host body, which may gain access through ulcerated junctional epithelium lining the periodontal pockets ${ }^{6}$.

It was found that atherogenesis and plaque instability can be inferred by increased levels of plasma markers for inflammation, as ascertained by C-reactive protein, which may be mediated by periodontal disease. Recent studies have indicated that periodontal treatment could reduce plasma levels of C-reactive protein and interleukin-6 ${ }^{10,11}$, improve endothelial function ${ }^{17,37,48,54}$ and improve periodontal health conditions, but without concomitant reduction in systemic levels of C-reactive protein when compared to the untreated control population.

Although the findings of the present study seem to be considerably relevant, other studies are necessary to confirm the role of periodontal pathogens in the development of atheromatous plaques, to more fully understand the mechanisms linking periodontal disease with cardiovascular diseases. 


\section{CONCLUSIONS}

Stroke patients had deeper pockets, more severe attachment loss, increased bleeding on probing, increased plaque indexes, and their pockets harbored increased levels of Porphyromonas gingivalis. These findings suggest that periodontal disease is a risk factor for the development of cerebral hemorrhage or infarction. Early treatment of periodontitis may counteract the development of cerebrovascular episodes.

\section{ACKNOWLEDGEMENTS}

The authors thank Dr. José Roberto Pereira Lauris for his statistical analysis. The authors also thank FAPESP (The State of São Paulo Research Foundation, process number: 2006/02376-4) and CAPES (Coordination of Support for Higher Education) for financially supporting this study.

\section{COMPETING INTERESTS}

The authors declare no competing interests.

\section{REFERENCES}

1- Ainamo J, Bay I. Problems and proposals for recording gingivitis and plaque. Int Dent J. 1975;25:229-35.

2- Albandar JM. Periodontal diseases in North America. Periodontol 2000. 2002;29:31-69.

3- Armitage GC. Periodontal infections and cardiovascular diseasehow strong is the association? Oral Dis. 2000;6:335-50.

4- Ashimoto A, Chen C, Bakker I, Slots J. Polymerase chain reaction detection of 8 putative periodontal pathogens in subgingival plaque of gingivitis and advanced periodontitis lesions. Oral Microbiol Immunol. 1996;11:266-73.

5- Beck JD, Offenbacher S. Systemic effects of periodontitis: epidemiology of periodontal disease and cardiovascular disease. J Periodontol. 2005;76:2089-100.

6- Beck JD, Slade GD. Epidemiology of periodontal diseases. Curr Opin Periodontol. 1996;3:3-9.

7- Boutaga K, Savelkoul PH, Winkel EG, van Winkelhoff AJ. Comparison of subgingival bacterial sampling with oral lavage for detection and quantification of periodontal pathogens by real-time polymerase chain reaction. J Periodontol. 2007;78:79-86.

8- Cavrini F, Sambri V, Moter A, Servidio D, Marangoni A, Montebugnoli $\mathrm{L}$, et al. Molecular detection of Treponema denticola and Porphyromonas gingivalis in carotid and aortic atheromatous plaques by FISH: report of two cases. J Med Microbiol. 2005;54:936.

9- Cortelli SC, Feres M, Rodrigues AA, Aquino DR, Shibli JA, Cortelli JR. Detection of Actinobacillus actinomycetemcomitans in unstimulated saliva of patients with chronic periodontitis. J Periodontol. 2005;76:204-9.

10- D'Aiuto F, Nibali L, Parkar M, Suvan J, Tonetti MS. Short-term effects of intensive periodontal therapy on serum inflammatory markers and cholesterol. J Dent Res. 2005;84:269-73.

11- D'Aiuto F, Ready D, Tonetti MS. Periodontal disease and C-reactive protein-associated cardiovascular risk. J Periodontal Res. 2004;39:236-41.

12- Danesh J, Muir J, Wong YK, Ward M, Gallimore JR, Pepys MB. Risk factors for coronary heart disease in acute-phase proteins. A population-based study. Eur Heart J. 1999;20:954-9.
13- Davenport ES, Williams CE, Sterne JA, Sivapathasundram V, Fearne JM, Curtis MA. The East London Study of Maternal Chronic Periodontal Disease and Preterm Low Birth Weight Infants: study design and prevalence data. Ann Periodontol. 1998;3:213-21. 14- Deshpande RG, Khan MB, Genco CA. Invasion of aortic and heart endothelial cells by Porphyromonas gingivalis. Infect Immun. 1998;66:5337-43.

15- Desvarieux M, Demmer RT, Rundek T, Boden-Albala B, Jacobs DR Jr, Sacco RL, et al. Periodontal microbita and carotid intima-media thickness: the Oral Infections and Vascular Disease Epidemiology Study (INVEST). Circulation. 2005;111:576-82. 16- Dorn BR, Dunn WA Jr, Progulske-Fox A. Invasion of human coronary artery cells by periodontal pathogens. Infect Immun. 1999;67:5792-8.

17- Elter JR, Hinderliter AL, Offenbacher S, Beck JD, Caughey M, Brodala $\mathrm{N}$, et al. The effects of periodontal therapy on vascular endothelial function: a pilot trial. Am Heart J. 2006;151:47.

18- Elter JR, Offenbacher S, Toole JF, Beck JD. Relationship of periodontal disease and edentulism to stroke/TIA. J Dent Res. 2003;82:998-1001.

19- Epstein SE, Zhou YF, Zhu J. Infection and atherosclerosis: emerging mechanistic paradigms. Circulation. 1999;100:e20-8. 20- Ferreira SB Jr, Trombone AP, Repeke CE, Cardoso CR, Martins W Jr, Santos CF, et al. An interleukin-1beta (IL-1beta) singlenucleotide polymorphism at position 3954 and red complex periodontopathogens independently and additively modulate the levels of IL-1beta in diseased periodontal tissues. Infect Immun. 2008;76:3725-34.

21- Garant PR. Light and electron microscopic observations of osteoclastic alveolar bone resorption in rats monoinfected with Actinomyces naes/undii. J Periodontol. 1976;47:717-23.

22- Goodson JM, Tanner AC, Haffajee AD, Sornberger GC, Socransky SS. Patterns of progression and regression of advanced destructive periodontal disease. J Clin Periodontol. 1982;9:472-81. 23- Grau AJ, Becher H, Ziegler CM, Lichy C, Buggle F, Kaiser C, et al. Periodontal disease as a risk factor for ischemic stroke. Stroke. 2004;35:496-501

24- Haffajee AD, Cugini MA, Tanner A, Pollack RP, Smith C, Kent RL $\mathrm{J} r$, et al. Subgingival microbiota in healthy, well-maintained elder and periodontitis subjects. J Clin Periodontol. 1998;25:346-53. 25- Hansson GK, Robertson AK, Söderberg-Nauclér C. Inflammation and atherosclerosis. Annu Rev Pathol. 2006;1:297-329.

26- Haraszthy VI, Zambon JJ, Trevisan M, Zeid M, Genco RJ. Identification of periodontal pathogens in atheromatous plaques. J Periodontol. 2000;71:1554-60.

27- Heijl L, Rifkin BR, Zander HA. Conversion of chronic gingivitis to periodontitis in squirrel monkeys. J Periodontol. 1976;47:710-6. 28- Herzberg MC, Weyer MW. Dental plaque, platelets, and cardiovascular diseases. Ann Periodontol. 1998;3:151-60.

29- Hugoson A, Jordan T. Frequency distribution of individuals aged 20-70 years according to severity of periodontal disease. Community Dent Oral Epidemiol. 1982;10:187-92.

30- Jeffcoat MK, Hauth JC, Geurs NC, Reddy MS, Cliver SP, Hodgkins PM, et al. Periodontal disease and preterm birth: results of a pilot intervention study. J Periodontol. 2003;74:1214-8.

31- Joshipura KJ, Hung HC, Rimm EB, Willett WC, Ascherio A. Periodontal disease, tooth loss, and incidence of ischemic stroke. Stroke. 2003;34:47-52

32- Kozarov E, Sweier D, Shelburne C, Progulske-Fox A, Lopatin D. Detection of bacterial DNA in atheromatous plaques by quantitative PCR. Microbes Infect. 2006;8:687-93.

33- Kristensen B, Malm J, Carlberg B, Stegmayr B, Backman C, Fagerlund $M$, et al. Epidemiology and etiology of ischemic stroke in young adults aged 18 to 44 years in northern Sweden. Stroke. 1997;28:1702-9.

34- Lamont RJ, Yilmaz O. In or out: the invasiveness of oral bacteria. Periodontol 2000. 2002;30:61-9.

35- Lindsberg PJ, Grau AJ. Inflammation and infections as risk factors for ischemic stroke. Stroke. 2003;34:2518-32. 
36- Loe H, Holm-Pedersen P. Absence and presence of fluid from normal and inflamed gingival. Periodontics. 1965;149:171-7. 37- Mercanoglu F, Oflaz H, Oz O, Gökbuget AY, Genchellac H, Sezer $M$, et al. Endothelial dysfunction in patients with chronic periodontitis and its improvement after initial periodontal therapy. J Periodontol. 2004;75:1694-700.

38- Morrison HI, Ellison LF, Taylor GW. Periodontal disease and risk of fatal coronary heart and cerebrovascular diseases. J Cardiovasc Risk. 1999;6:7-11.

39- Nencini P, Inzitari D, Baruffi MC, Fratiglioni L, Gagliardi R, Benvenuti $L$, et al. Incidence of stroke in young adults in Florence, Italy. Stroke. 1988;19:977-81.

40- Offenbacher S, Barros SP, Paquette DW, Winston JL, Biesbrock $A R$, Thomason RG, et al. Gingival transcriptome patterns during induction and resolution of experimental gingivitis in humans. J Periodontol. 2009;80:1963-82.

41- Offenbacher S, Beck JD. A perspective on the potential cardioprotective benefits of periodontal therapy. Am Heart J. 2005; 149:950-4.

42- Offenbacher S, Beck JD, Moss K, Mendoza L, Paquette DW, Barrow DA, et al. Results from the Periodontitis and Vascular Events (PAVE) Study: a pilot multicentered, randomized, controlled trial to study effects of periodontal therapy in a secondary prevention model of cardiovascular disease. J Periodontol. 2009;80:190-201. 43- Offenbacher S, Katz V, Fertik G, Collins J, Boyd D, Maynor G, et al. Periodontal infection as a possible risk factor for preterm low birth weight. J Periodontol. 1996;67:1103-13.

44- Page RC, Offenbacher S, Schroeder HE, Seymour GJ, Kornman KS. Advances in the pathogenesis of periodontitis: summary of developments, clinical implications and future directions. Periodontol 2000. 1997;1997:216-48.

45- Pussinen PJ, Alfthan G, Rissanen $\mathrm{H}$, Reunanen A, Asikainen $S$, Knekt P. Antibodies to periodontal pathogens and stroke risk. Stroke. 2004;35:2020-3.

46- Ridker PM, Glynn RJ, Hennekens CH. C-reactive proteins adds to the predictive value of total and HDL cholesterol in determining risk of first myocardial infarction. Circulation. 1998;97:2007-11. 47- Sakai VT, Campos MR, Machado MA, Lauris JR, Greene AS, Santos CF. Prevalence of four putative periodontopathic bacteria in saliva of a group of Brazilian children with mixed dentition: 1-year longitudinal study. Int J Paediatr Dent. 2007;17:192-9.
48- Seinost G, Wimmer G, Skerget M, Thaller E, Brodmann M, Gasser R, et al. Periodontal treatment improves endothelial dysfunction in patients with severe periodontitis. Am Heart J. 2005; 149:1050-4.

49- Socransky SS, Haffajee AD, Cugini MA, Smith C, Kent RL Jr. Microbial complexes in subgingival plaque. J Clin Periodontol. $1998 ; 25: 134-44$.

50- Socransky SS, Haffajee AD, Goodson JM, Lindhe J. New concepts of destructive periodontal disease. J Clin Periodontol. 1984;11:21-32.

51- Socransky SS, Haffajee AD, Ximenez-Fyvie LA, Feres M, Mager D. Ecological considerations in the treatment of Actinobacillus actinomycetemcomitans and Porphyromonas gingivalis periodontal infections. Periodontol 2000. 1999;20:341-62.

52- Söder PO, Söder B, Nowak J, Jogestrand T. Early carotid atherosclerosis in subjects with periodontal diseases. Stroke. 2005;36:1195-200.

53- Syrjänen J, Peltola J, Valtonen V, Iivanainen M, Kaste M, Huttunen JK. Dental infections in association with cerebral infarction in young and middle-aged men. J Intern Med. 1989;225:179-84

54- Tonetti MS, D'Aiuto F, Nibali L, Donald A, Storry C, Parkar M, et al. Treatment of periodontitis and endothelial function. $\mathrm{N}$ Engl J Med. 2007;356:911-20.

55- Umeda M, Contreras A, Chen C, Bakker I, Slots J. The utility of whole saliva to detect the oral presence of periodontopathic bacteria. J Periodontol. 1998;69:828-33.

56- Wu T, Trevisan M, Genco RJ, Dorn JP, Falkner KL, Sempos CT. Periodontal disease and risk of cerebrovascular disease: the first national health and nutrition examination survey and its follow-up study. Arch Intern Med. 2000;160:2749-55.

57- Zaremba M, Górska R, Suwalski P, Kowalski J. Evaluation of the incidence of periodontitis-associated bacteria in the atherosclerotic plaque of coronary blood vessels. J Periodontol. 2007;78:322-7. 58- Zétola VHF, Nóvak EM, Camargo CHF, Carraro Júnior $\mathrm{H}$, Coral $\mathrm{P}$, Muzzio JA, et al. Acidente vascular cerebral em pacientes jovens. Arq Neuropsiquiatr. 2001;59:740-5. 